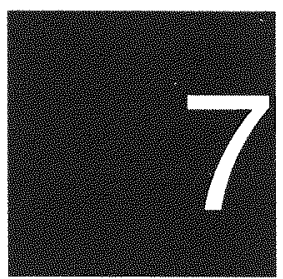

\title{
Business as unusual
}

\author{
Glenn Banks
}

This chapter presents the results of four weeks fieldwork at Porgera during March 1994, arising in part from a recognition that my earlier account of the cash economy (Chapter 3 ) had not adequately addressed the role of 'business'. Since 1990, the value of Porgera Joint Venture (PJV) business contracts to local Porgeran businesses had been equivalent to the value of all cash payments made by the company in the form of compensation, wages and royalties. Given its size, political importance and recent history, the business sector in Porgera was a major 'issue' in the local community.

My earlier discussion of this issue left a number of important questions unresolved.

- Were the businesses owned by Porgerans, or did they lease them to, or act as front-men for, larger non-Porgeran business interests?

- Were the 'Porgeran' business owners native to the Porgera Valley or were they 'new' Porgerans?

- How were the businesses run, did they have light or heavy debt burdens, and what was being done with the profits?

The rationale for the present study was to

- provide an independent review for the company, the government and the local community of the results of five 
years of business development at Porgera associated with the construction and operation of the Porgera gold mine

- provide background material for the review of the Porgera Joint Venture's Business Development Plan; and

- provide a baseline against which the future growth and development of the business sector in Porgera could be monitored.

A variety of methods were employed in this study. A survey of all formal businesses in the valley was carried out in March 1994, locating them on a series of maps, interviewing the owners and establishing a database for future information. Our definition of a 'formal' business entailed the possession of a large asset such as a building, public motor vehicle (PMV) or plant of some kind, thus excluding market traders and sellers of second-hand clothes (see Chapter 2).

In some cases, the owners were not available, in which case the interviews were held with the manager or staff of the business. Information collected included: the type and ownership of the business; its history (including the origin of the initial capital); the value of stock, turnover, cash, credit, profits and investments; the extent and nature of debt; the accounting system used; business or management training levels; employees and wages; problems being faced; the owner's future plans; and the type of assistance required from the government and the mining company.

As with all surveys of this type, the quality of the information collected relies heavily on the honesty and knowledge of the owner concerned. For nearly all the smaller operations, the information relating to turnover, profit, credit and stock levels is the store owner's own estimate, and in some cases these appear unlikely. Usually, these are cases where the owner had little idea of the figures concerned, rather than a deliberate intention to mislead, and this serves to underline the informal way in which these 'formal' business operations were being run. In most cases, we were able to check that the figures for stock were reasonably accurate, simply by looking at the amount of stock on the shelves. Occasionally, lists of customers with outstanding credit were displayed or produced for us to check. The relative number of customers in different stores could be roughly confirmed simply by counting the number who entered during the 2030 minutes that we were in the store carrying out the interview.

The information collected on each business varied along a continuum, from those where only the basic dimensions of the 
building and its location were recorded, through those where we were able to collect limited information about its ownership, to those where the entire questionnaire was completed. Some businesses were missed as a result of our reliance on the road system: for example, four small closed trade stores were present in the Kaiya LMP area in late 1993 (see Chapter 6). On the other hand, PMV business owners were virtually impossible to interview because they spent most of the day driving. However, most business operations with fixed assets were located very close to the road.

PJV records of all formal business contracts (excluding labour-only contracts) were analysed and discussed with a range of parties, including landowner representatives. Discussions about business at Porgera were held with a number of people, including PJV staff, Porgera Development Authority staff, business owners and managers, landowner representatives, and Enga Provincial Government staff. Several significant Porgeran businessmen ${ }^{1}$ were interviewed in depth, to provide 'profiles' and to gain an insight into the factors behind their relative success. Finally, a return visit to Porgera on unrelated fieldwork in late 1994 allowed the opportunity to update and correct the data in an earlier draft.

\section{Business at Porgera: some issues}

In this section, I discuss some general issues which have influenced the development of business at Porgera. These include the philosophy behind business development, the basic constraints of both the Porgeran setting and the mine development, the limitations of Porgeran attitudes to business, and the issue of umbrella companies verses multiple business entities.

\section{The philosophy of business development at resource projects}

Local and provincial business development has been an integral part of resource developments in Papua New Guinea for some time. Initially, the mining development agreements placed emphasis on the local (i.e. Papua New Guinea) supply of goods, along with employment, training and localisation issues. Included in the original 1967 Bougainville Copper Agreement was a requirement (Clause 9(a)) that, 'so far as is reasonably and economically practical', the company should use supplies, plant, machinery and equipment manufactured or produced in the country. The renegotiated 1974 agreement contained a new clause (Clause 10A) which related to the conduct of 
the company's business advisory services. These were to be made available on 'as widespread a basis as is reasonably possible to all areas of the Bougainville District'. The second and final section of this clause stated that the company 'shall not be required to spend more on its said business advisory services in any year than the amount so spent by it in the year ending the 31st December 1974'.

The original 1976 Ok Tedi Agreement contained a large section on local business development. In summary, this stated that

- the company was to promote, support, encourage and lend assistance to establishment of local businesses in the area, particularly those enterprises supplying goods and services to the project or the town

- the company was not obliged to lend money to any enterprise

- maximum use was to be made of Papua New Guinean subcontractors, where the price and quality of the service was comparable to those obtainable from elsewhere

- insofar as it was practical, the company was to give first preference to landowners

- at least one full time, experienced business development staff member was to be employed by the company

- a business development programme was to be prepared, making provision, where practical, for various specified contracting services, for training, and for various types of activities and assistance by the company; and

- the business development programme was to be reviewed annually, with a view to 'securing the maximum benefit to Papua New Guineans and local enterprises from the operations of the Company and the carrying out of the Project'.

A draft of the Standard Mining Development Agreement which was prepared in late 1985 adopted the Ok Tedi requirements in Clause 21, relating to local supplies and business development.

The Mining Development Contract for the Porgera mine development contained one clause (Clause 14) relating to local business development. This clause provided the formal context for the PJV business development programme

14.1 The Joint Venturers, in consultation and co-operation with the State and the Engan Provincial Government, will:

(a) Within nine (9) months of the effective date (12th May 1989), devise

a business development programme which will encourage and assist 
people from the Enga Province with preference to Porgerans, to establish businesses to supply materials, equipment and services to the Project, provided that the Joint Venturers shall not be obliged to grant or lend money or provide materials to any person or organisation,

(b) Conduct an annual review of progress being made on the implementation of the business development programme and make such variations to it as may be required by changing circumstances, and

(c) Employ full-time staff experienced in setting up and managing business enterprises

i) To assist Papua New Guineans who wish to or have set up businesses to service the project;

ii) To assist in the implementation of the business development programme and variations thereof;

iii) To liaise with the appropriate officials from the State and the Enga Province; and

iv) To provide advice and assistance in the development and implementation of long-term business enterprises which can continue after the Project is terminated.

Similarly worded clauses were included in the agreements between the national government and the Enga Provincial Government, and between the national government and the Porgera landowners.

Such negotiated guidelines and agreements are generally very broad, but in all cases they reflect a concern from the government that the projects provide a basis for local business development. A report by the International Monetary Fund (IMF) prepared for the Papua New Guinea government in 1993 pointed out that business development programs and favoured status for PNG suppliers amounted to 'implicit taxes' on the operator which effectively lowered the national government's own taxation revenue from the project. The IMF believed that such implicit taxes were better replaced by direct income taxes (Callick 1993:4). O'Faircheallaigh (1985:238) has offered a different perspective, noting that

It can be argued that a number of LDCs [including PNG] have concentrated too heavily on a revenue-maximising strategy and that the limited 'direct' economic impact of mining is in part due to their consequent failure to exploit other economic opportunities generated by mineral development.

Business development has been included in the agreements, and as an integral part of the overall approach to new resource developments, largely in response to pressure from the local community and the relevant provincial government. These parties have been concerned to see that they are able to derive maximum economic benefits from the 
mine development, thus excluding others from obtaining a greater share.

Mining companies have had additional motivations for becoming involved in local business development. Clearly, there are economic advantages in having local businesses which are able to supply goods and services to the mining project at competitive rates. In addition, local business development contributes to the maintenance of a social environment conducive to the continuation of the resource project, and to mitigating its social impact. This is an important factor, because it highlights the social and political objectives which underpin business development programs at least as much as their economic objectives.

\section{Basic business parameters at Porgera}

There are a number of basic constraints to business development at Porgera-location, the pre-existing economy, the nature of the mine development, educational standards, the social environment, and land availability.

The location of Porgera, $130 \mathrm{~km}$ west of Mount Hagen at the end of the Enga Highway, places severe economic constraints on business development. Transport costs alone effectively rule out the development of manufacturing industries which are able to compete nationally or even regionally. The proposed Porgera-Tari road would reduce this constraint to some extent, placing Porgera in a more central location in a regional sense, but the timetable for its construction was unclear in 1994 (and is still unclear today). Of course, Porgeran businesses are located close to the mine itself, and this has conferred advantages on those businesses which are able to offer goods and services to the mine. Theoretically, if not practically, Porgeran businesses should be well placed to compete with Engan and other Papua New Guinean companies for contracts from the company.

The physical environment at Porgera places constraints on business development in the area. Firstly, the high altitude, soils and climate of the area severely limit its potential for cash cropping (Pacific Agribusiness 1987[1]:31-6). There is also a serious lack of stable, relatively flat land, a problem underlined by the 1991 landslip at Porgera Station itself. On the positive side, the impressive scenery of the area could potentially be used as a basis for tourism, and there is some possibility for commercial vegetable production, particularly at the lower altitudes. 
There was a limited amount of business activity in Porgera prior to the start of mine construction, but the small scale of the existing business sector has continued to act as a constraint on its further development. While a larger business sector might have conferred economies of scale on the whole area, the limited size of the sector has meant that few Porgerans are gaining the necessary skills in business management.

The nature of the mining operation itself places constraints on the types of businesses which are likely to be able to supply goods and services. The operation is a capital-intensive one, reliant on hightechnology capital equipment and specialised inputs and maintenance services. Much of the capital equipment and many of the inputs have to be sourced from offshore, or through specialised national firms. ${ }^{2}$ The most plausible area for local business is the supply of basic services-such as freighting, transport, supply of food, laundry services (Pacific Agribusiness 1987).

The 'fly-in fly-out' (FIFO) pattern of commuter mining for the nonlocal component of the project workforce has been a source of considerable concern in the local community. The belief has been that, with these workers and their families living in Porgera, there would be much greater scope for the development of local businesses. Money would 'stop' in Porgera rather than be spent in other parts of Papua New Guinea or offshore. A report by an economic consultant engaged by the Porgera Landowners' Association provides support for this argument, estimating that K12 million has been lost to Porgera each year as a result of the FIFO policy (Kiri Consultants 1993). The construction contracts alone for the additional houses required by a resident workforce would certainly have been a large boost for local contractors. However, I doubt whether the on-going economic advantages to Porgera would have been as large as predicted in that report. ${ }^{3}$ In any case, the 'FIFO debate' was not going to be decided on strictly economic grounds. Quality of life, safety, and other social issues have been more important than economic factors in determining where the bulk of the workforce resides.

Educational levels among Porgerans are generally low, and this counts against a locally-owned business sector. Experience from around the world suggests that, even with higher education levels and a business background, around 80 per cent of small businesses will fail in their first year. In the analysis of our own survey results, it was notable that the six largest businesses in Porgera were owned by 
people who spoke English. But the general lack of education and business experience were not problems which could be quickly overcome. While the low educational levels of Porgerans generally have meant that joint ventures with outside firms and individuals can be an attractive proposition, they have also meant that many Porgerans are vulnerable to sharp operators, many of whom have come to Porgera with attractive sounding deals for local businessmen.

The current social environment at Porgera is not conducive to the development of a large business sector. Clearly, the low population base of the valley (an estimated 12,000 people) places a limit on the size and scope of those businesses which are economically viable. In addition, the high level of personal violence and inter-clan fighting are disincentives to investment in Porgera by both outsiders and Porgerans. The costs of security measures, from fences to security guards, are high, while the risk of damage to plant, violence against staff, and theft of stock all act as disincentives.

Land, or more precisely the lack of relatively stable freehold or leasehold, has also been a major constraint to the development of a business sector in Porgera. The lack of secure access to land has discouraged a number of large outside businesses from locating in Porgera. Locating on customarily owned land adds a further level of complexity to the operation of a business. While Porgerans themselves are more easily able to locate business operations on their own clan land, banks are generally reluctant to lend to businesses without freehold or leasehold title.

\section{Umbrella companies versus multiple entities}

Around all major resource projects, the developer faces the issue of whether to establish and support an umbrella landowner company or to utilise multiple entities which reflect tribal or clan differences. One business development consultant has offered several reasons for considering 'a single entity to be the best means of representing the local people's interest in [dealing] with a developer' (Egan 1994:4), including reduced inter-clan jealousy, a focus for the developer's attention, a pooling of financial resources, and a uniting influence. The umbrella stands as a symbol of the local community's involvement in development alongside the mining operation. An umbrella company can also serve as a role model for local business people, ideally illustrating how an effective business operates. It is also possible for an umbrella company to establish a series of small businesses to which it can provide advice and assistance 
until it is deemed appropriate to sell the business to the manager(s)-in essence acting as a 'business incubator'.

On the other hand, the umbrella company concept has several problems. It means putting all your eggs in one basket, and if it gets into trouble (as has happened at Bougainville, Ok Tedi, Misima and Porgera), this can count against the mining company. Good practical management, suited to Papua New Guinea's social and cultural environment, is required and again the record on this count is not great. A single umbrella company can in some circumstances be seen as a branch of the mining operation, particularly if the mining company offers management services. Finally, the dividends paid by a large company with a broad base of shareholders are not likely to satisfy everyone, and there will be local entrepreneurs who feel they would benefit more from having their own dealings with the mining company.

In summary, there are advantages and disadvantages to each approach, and in theory it should be possible to have a successful blend of both. Under this scenario, the umbrella company picks up the larger contracts, while individuals and business groups pick up smaller ones. This is the approach which has been adopted at Porgera, and although business development has not met everyone's expectations, I do not believe that exclusive reliance on either an umbrella company or individual entities would have provided a better result.

\section{Bisnis is not business}

There are important cultural factors which impinge on the development and performance of the business sector at Porgera. These factors revolve around the understanding and expectations of 'business'. In large part, they derive from the pre-existing social and economic system of the Ipili. The prior economic system was based on mounded sweet potato production, which in turn was used for the raising of pigs. The product was partly for subsistence and partly for exchange and distribution, both to kin and to non-kin. These exchanges and distributions ranged from contributions to relatively structured forms of exchange, such as brideprice or death compensation payments, to more personal obligations to distribute food and other resources to immediate kin.

Wealth for a man was created through the production of pigs for the accumulation of wives, which then increased his capacity to 
produce more pigs for distribution. Prestige and status was in large part linked to distribution, and the extent of the obligations to himself which a man could build up. In this sense, then, the aim was to maximise net outgoings (Gregory 1980:636). Although rhetorical, political and fighting skills were also some of the criteria by which a man was judged, this conflation of the production system and social status-the entanglement of the economic and social spheres-is most significant for this discussion. Distribution of pigs and other goods by a man can be viewed as a form of investment-it created obligations for the recipients to eventually 'return' the investment (Finney 1987:10). But, as Gregory (1980) notes, it was an interest-free form of investment, which kept both parties in a state of 'mutual reciprocal dependence', and the repayment period was flexible.

The economy was based around a limited range of goods, and importantly, the 'leakage' of production out of the system was not great. There was some trade between Ipili and other language groups, particularly the Enga to the east and the Huli to the south, but it is not likely that the extent of resources traded were significant when compared to those used for internal distribution and consumption, and in any case, every outside trade transaction returned some resource to Porgera. There were entrepreneurs in the trading system: Ballard documents Huli traders who acted as middlemen, and through a series of exchanges of different goods in different parts of the valley, eventually obtained up to eight times as much as what they had originally traded (Ballard 1994:141). But this was done with the intention of putting the traded resources obtained back into the exchange and distribution network within Huli territory.

Planning was an integral part of the pre-contact socioeconomic system-from the planning of gardens (an annual cycle) to pig rearing (at least four years), trips for trade and karuka harvesting (probably irregular events), and perhaps most significantly, the planning associated with the ongoing maintenance of networks of exchange, distribution, obligation and reciprocity - both inside and outside Porgera.

There are several obvious conflicts between the pre-contact system and the operation of a business in the cash economy. The conflation of personal and productive systems, and the pressure of obligations to kin, drain resources away from a business. Maintenance of the exchange networks, with their emphasis on the maximising of net outgoings, clearly clashes with the system of modern business which 
seeks to maximise net incomings, especially as a means to accumulate capital (Pomponio 1992:181).

In addition, businessmen continually find themselves obligated to assist kin in a range of projects (brideprice, school fees, a bag of rice, and so on) in such a way that the owner is relying on repayments under the relatively flexible traditional system, while the business incurs debts in the formal economy. And yet it is often these same kin who contributed in some manner to ensure that the business was able to start in the first place.

It is also far easier for individual Porgeran businessmen to leak resources out of the local economy in a way which attains little or no benefit in either the traditional or modern sphere. Although conspicuous consumption of a Landcruiser, for example, may carry some prestige value within the community, there are no real benefits to an individual's business, in modern or traditional terms, from spending on overseas travel.

Expectations of business by Porgerans are also important. In large part, businesses are seen as a means by which a person can accumulate resources for use in the traditional sphere-such as wives and obligated kin and non-kin (see Finney 1987). Cash, assets and capital accumulation per se are not generally seen as ends in themselves, but rather as a tool which can be employed to acquire status within the community, either through distribution or conspicuous consumption, and to further the political aspirations of the businessman.

Individual Porgerans are constrained by, and are able to control, these factors to varying degrees in the running of their businesses. For Porgerans, they are part of the business environment-it is simply not possible to ignore them. The most successful businessmen are those who are able to successfully manage the extent to which these obligations and expectations impinge on the running of their business-a point which Finney (1987:63-4) has made about successful Gorokan businessmen.

The practical implication of all these issues is that, although many Porgerans have received large amounts of cash compensation from the mine development since 1989, this has not been transformed into a sustainable and viable business sector in Porgera. The reason lies in the pressures exerted by kin to distribute and contribute to exchange, and by the fact that leakage out of the system is far more likely with cash than it is with pigs. In light of my previous estimates of the use of 
compensation payments (Chapter 3), the remainder of this chapter will focus on the estimated 20-25 per cent which has been invested in local business, and will assess how effective this investment has been.

\section{Business development 1984-1994}

In this section I trace the development of business in Porgera over a period of ten years. The chronology is patchy, and as such is presented in three parts. In the first, a brief potted history is provided, drawing primarily on records at hand, particularly the Social and Economic Impact Study (SEIS) and notes taken by myself during several visits to Porgera. The second part traces the development of the umbrella Porgeran landowner company, Ipili Porgera Investments Pty Ltd (IPI). The rise and fall and rise of IPI provides an interesting illustration of many of the problems of businesses at Porgera, and particularly those associated with the mine development. The third part presents the result of a survey of all businesses in Porgera in March 1994, which revealed a number of trends symptomatic of the local business sector. Finally, I review the success of the 1990 PJV Business Development Plan and, with the benefit of hindsight, discuss its strengths and weaknesses.

\section{Business at Porgera: a brief history}

The following account is drawn largely from four reviews and surveys carried out in 1984, 1987, 1990-91 and 1992-94, respectively, and anecdotal information collected from PJV staff and local businessmen.

The first systematic review of the Porgera business sector is contained in Talyaga's (1984) socioeconomic impact study. He noted that the 1980 census showed 97 households in Porgera District operating trade stores. In 1984, there were 15 trade stores in Alipis alone, though only four of these were operating, and all were 'half empty'. Twelve of these were owned and operated by local families, and the other three by 'other ethnic groups'. All of these trade stores had been built with cash accumulated by the individual owners, most of which had come from the sale of gold. The 1980 census also found that 19 households in Porgera District operated PMV businesses. ${ }^{4}$ Again, these were owned and operated by individuals or families, although Talyaga (1984:82) notes that they had been purchased on a clan basis during the 1970s. They often operated at a loss due to 'unfamiliarity with economics of transport and lack of knowledge [of commerce]'. Apart from trade stores and PMVs, a sawmill at Alipis (owned by an outsider and commercially of little value) was the only 
other business activity recorded. Talyaga (1984) concluded the economic section of his report by stating that people were participating in the cash economy, often being guided by traditional values. There was plenty of cash around but 'people lack the knowledge to utilise it properly' (Talyaga 1984:83).

The SEIS (Pacific Agribusiness 1987) reported the results of a survey by the PJV Business Development section, which counted 143 trade stores, 93 of which were operating. On the other hand, it found that only seven vehicles were now owned by Porgerans. A number of business groups and companies were active in Porgera by this time. Several of these had sold 'shares' to Porgerans, though share certificates were rarely issued. These included

- Ipili Timbers, which operated two mobile sawmills, employing 18 local people. It was owned by a man from Mount Hagen who had married into the Tieni clan. It was an important source of timber for the PJV during mine construction. However, its inability to secure access to a timber resource at reasonable rates was a problem; at one point, leases were issued to two different groups for the same resource. The business ceased operating in 1992.

- Porgera Brothers and Exploration Pty Ltd was a gold-buying operation set up by a Tari man, who had married into the Alapklain clan, in conjunction with a national Member of Parliament. Porgera Enterprises Pty Ltd was set up by the same two men, and had entered into a joint venture with a Singapore-based group to sluice for gold. Equipment (valued at $\mathrm{K} 30,000$ ) had arrived at Porgera, but the company had no mining lease, nor even permission from the local landowners, and the enterprise had folded. The remains of the equipment were still present on the road below Mungalep in 1994.

- Aiyene Mine Explorations Pty Ltd was formed by members of the Waiwa, Tieni and Tuanda clans to act as an umbrella company for the Special Mining Lease (SML) landowners. Its purpose was primarily to win contracts associated with the mine development. Problems were experienced when it was discovered that control of the company effectively rested with outside interests.

- Ipili Amena was a company formed by the Anga and Kewai clans of Yuyan to operate trade stores, mining and transport 
services. Porgera Joint Venture (not to be confused with the mining company) was formed as an offshoot of Ipili Amena after an internal argument. In a joint venture with Basu Coffee, a large steel bulk store was built at Porgera Station, but an argument over the ownership of the land on which it was located meant that it was unable to operate.

- Porgera Yutane Business Group was a Mungalep-based private company, the chairman of which was also the chairman of IPI. This group had interests in gold buying, transport and a trade store, and had plans for a bus service, contracts with the PJV or IPI, a picture theatre, and the construction of houses for rent. This business later became part of Kutato Family Trading.

- Mandi Golden Business Group was established to carry out mining, operate a trade store, and establish a piggery.

- Alipis Development Corporation was an unregistered company, established by five Tieni people. At the time, they were operating a successful trade store (for which they had taken out a K1,500 loan) and running a Dyna truck. They had plans to expand into coffee and vegetable buying, the operation of a bakery, and the purchase of a 16-seater bus to travel between Porgera and Laiagam.

A subsequent trade store survey carried out by the PJV Business Development section in 1990-91 found a total of 72 operating stores in the Porgera Valley at that time, excluding the larger wholesale or retail businesses. Figure 7.1 shows the geographical spread of weekly turnover and stock levels measured in this survey. In the accompanying brief report, the author noted constraints on the accuracy of the data that were collected, similar to those I have previously noted for my own survey data. But it is clear that Porgera Station and Suyan were the major centres of retail activity at that time, while the ratio of stock levels to turnover appeared to be high throughout the valley.

\section{Inventory of existing businesses in Porgera}

During the fieldwork conducted in March 1994, I undertook a survey of all the existing business operations in the area. This involved driving along the roads, from Tipinini westwards, noting the details of all commercial structures and, in those cases where the owner was present and willing to be interviewed, asking a series of questions relating to the business. The entire Porgera Valley was covered over a 


\section{Figure 7.1 PJV trade store survey findings, 1990-91}

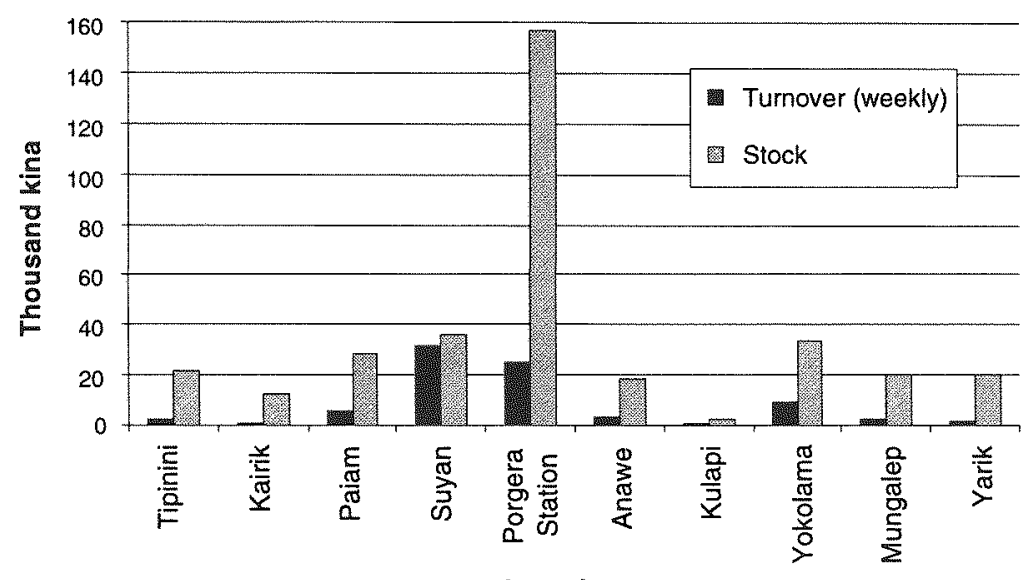

Location

Source: Porgera business survey.

two-week period. For the purposes of analysis, the valley was divided into 11 smaller areas (see Map 7.1). The information on each business was entered into a spreadsheet, its location was noted on a map, and in many cases a photograph was taken to facilitate the construction of a database on formal business activity in the valley.

In total, 382 business premises were noted during the survey. In a number of cases, more than one type of business was recorded for each premises, the most popular combination being that of the trade store and ' $k a i$ bar' (fast food outlet), of which there were 11 examples, mostly around Porgera Station. One hundred and nineteen business owners were interviewed, and details of ownership were found for 234 businesses. It is worth reiterating the types of business which, for one reason or another, were not included in the survey. These were

- market and roadside sellers

- PMV and labour-contracting businesses

- businesses at some distance from a road; and

- a number of ephemeral businesses which may have been mapped but whose owners were not interviewed because they were not open at the time of the survey. 


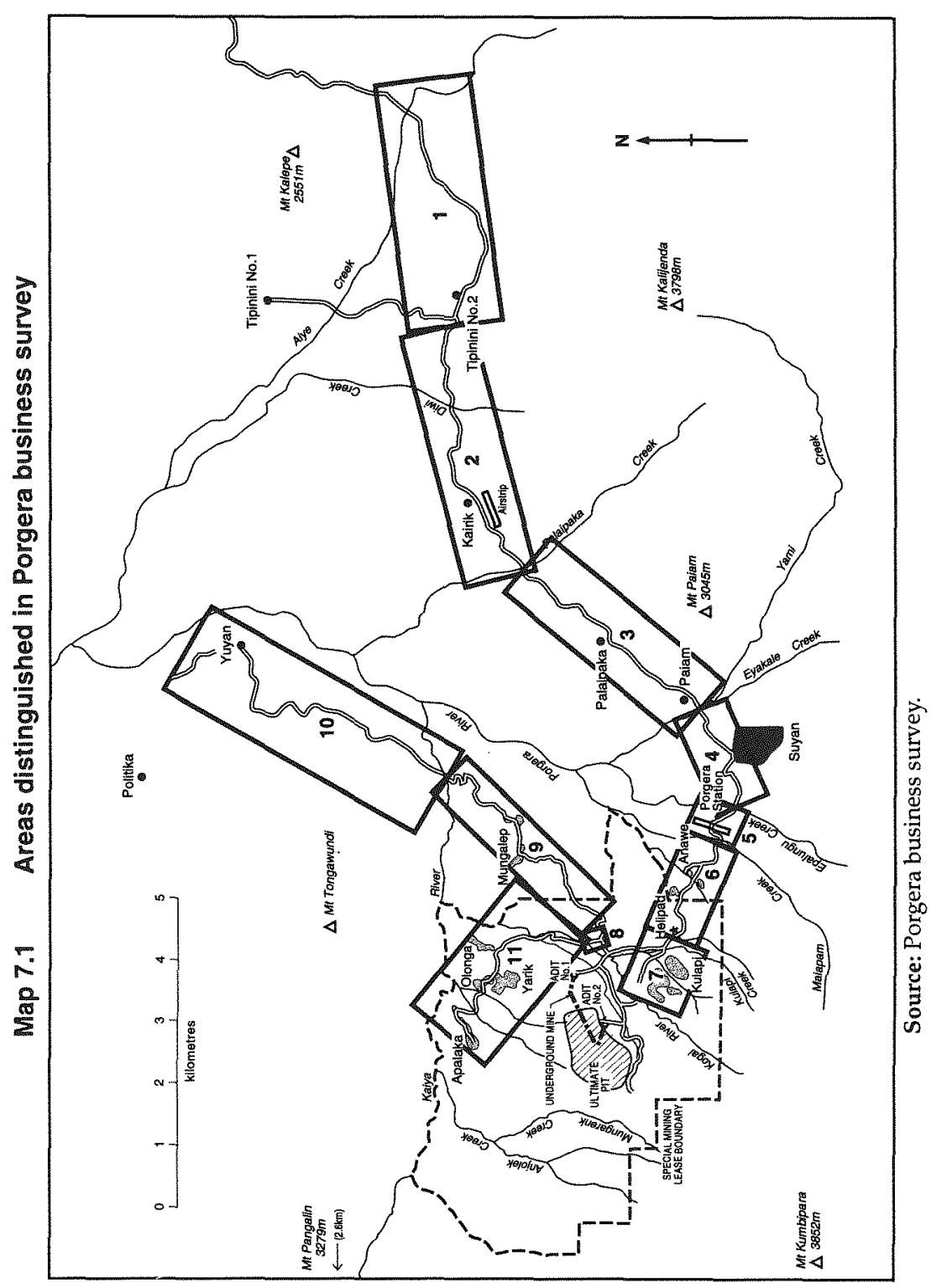


In addition, there were six trade stores whose owners were present but declined to be interviewed. Two large wholesale/retail businesses (the IPI Supa Stoa and Paiam Kumbipara Enterprises) were not included in this particular survey, but relevant data were collected later in separate interviews, and are included in the discussion which follows the presentation of the survey figures.

The following analysis is divided into three parts. In the first, significant findings from the aggregate figures are discussed. In the second, the businesses are divided geographically, because there are interesting and important differences in the figures for each area. Finally, the sample is divided into several different categories of business enterprise, which is another useful way in which to analyse the current business sector in Porgera.

The following figures emerge from the aggregate data.

- There were 284 trade stores (120 of which were open); 36 local bakeries; 28 fuel stations; 8 tyre repair shops; 5 chicken projects; 3 gold buyers; and 2 sawmills.

- A total initial investment of $\mathrm{K} 372,000$, or an average of $\mathrm{K} 3,680$ per business, was recorded for a total of 101 businesses.

- General savings were the most common source of seed capital, accounting for 38 per cent of businesses. This was followed by wages and alluvial gold earnings (22 per cent each), PJV compensation (16 per cent), sale of cash crops (10 per cent), wantoks ( 6 per cent), and a bank loan (5 per cent). Although general savings were the most common source of capital for both Porgerans and non-Porgerans, Porgerans were more likely to have used PJV compensation and alluvial gold earnings, while non-Porgerans relied more on wages.

- Cash holdings of $\mathrm{K} 57,000$ (an average of $\mathrm{K} 550$ per business) was recorded for a total of 103 businesses. Bank balances of $\mathrm{K} 312,000$ (an average of $\mathrm{K} 9,450$ per business) was recorded for the 33 businesses which had a separate passbook.

- The stock levels of 211 businesses were recorded, but 91 of these were businesses which were closed and we were informed that they had no stock. For those which were open, the total stock was valued at $\mathrm{K} 167,000$, or an average of $\mathrm{K} 1,390$ per business.

- For the 116 businesses which gave credit, the total credit 
outstanding was $\mathrm{K} 144,000$, or an average of $\mathrm{K} 1,240$ per business. Only 15 businesses (or 11 per cent of those interviewed) gave no credit.

- Eight businesses had debts totalling K55,200 (an average of K6,900 each), while 103 businesses had no debts.

- There was a total weekly turnover of $\mathrm{K} 73,000$ for 115 businesses interviewed, or an average of $\mathrm{K} 635$ per business. There were an estimated 4,000 customers daily, while the businesses had 61 paid staff and 117 unpaid staff.

- Sixty-four of the businesses had electricity, of which 35 used small generators. Porgeran owners accounted for 66 per cent of those with electricity. Forty-four businesses had vehicles, and 45 had freezers.

- Sixteen out of 119 owners interviewed had some business training, while 89 wanted to attend courses on how to run a business. Nine of the businesses had current tax compliance certificates.

The geographical pattern of business activity shows some striking differences between areas. The turnover, stock and credit levels by area are shown in Figure 7.2. The figures for Paiam Kumbipara and the IPI Supa Stoa have been added to those found in the main survey, and underline the fact that the commercial heart of Porgera is the Station area. Indeed, it seems to have become even more dominant than it was in 1990-91, though this situation was likely to change with the development of the Paiam township.

There was also a significant difference between the areas along the main road leading up to the SML (from Tipinini through to Anawe) and those within or through the SML (Kulapi to Yuyan and Apalaka). This point is highlighted in Table 7.1, which divides the survey data between these two geographical areas. Clearly, the first of these areas has a more professional business sector, with more trained managers, more paid employees, higher weekly turnover and, most strikingly, a far higher level of business bank savings. This appears to equate with a significantly lower percentage of Porgeran business owners, implying that 'outsiders' with business experience are taking a significant share of the Porgeran business sector. It is notable that Yokolama, the one location within the SML which has a low percentage of Porgeran owners (46 per cent), is also the location within the SML which has the highest turnover and highest credit levels. It is likely that turnover would have been increasing for short 


\section{Figure 7.2 Business turnover by area, 1994}

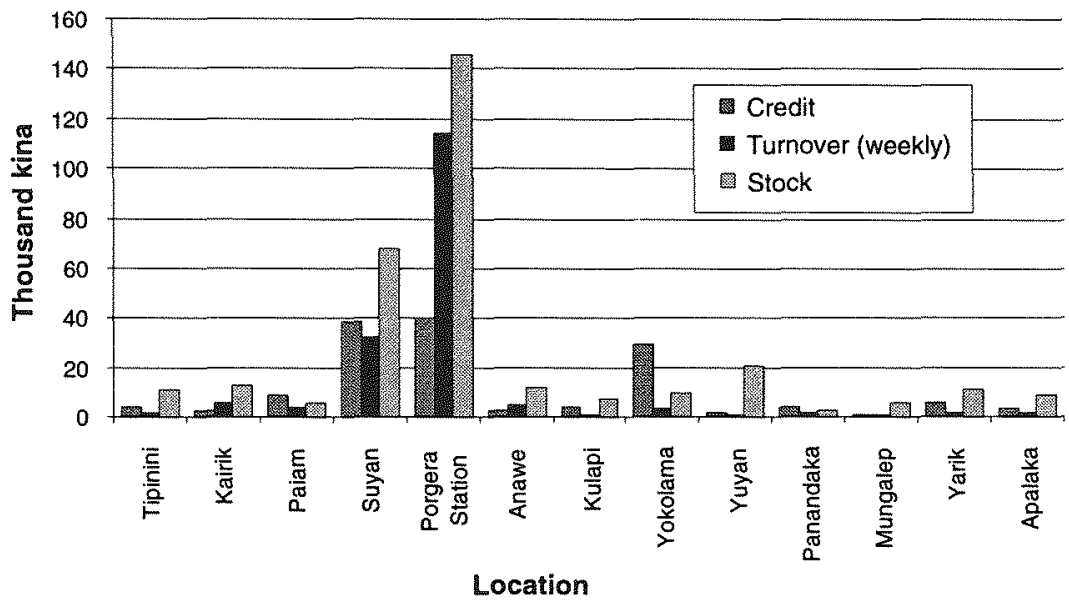

Source: Porgera business survey.

Table 7.1 Summary of differences in business activity by area, 1994

$\begin{array}{lll} & \text { Up to the SML } & \text { In or through the SML } \\ \text { Number of businesses } & 209 & 173 \\ \text { Number interviewed } & 69 & 50 \\ \text { Percentage Porgeran owned } & 60 & 88 \\ \text { Initial capital investment } & \text { K256,004 (average 4,196) } & \text { K115,859 (average } \\ 2,896 \text { ) } & & \\ \text { Weekly turnover } & K 62,500 \text { (average 961) } & \text { K10,710 (average 214) } \\ \text { Cash holdings } & K 43,332 \text { (average 774) } & \text { K13,417 (average 285) } \\ \text { Money in bank } & K 307,598 \text { (average 11,830) } & K 4,000 \text { (average 571) } \\ \text { Customers } & 2,849 \text { (average 43) } & 1,006 \text { (average 22) } \\ \text { Trained managers } & 15 & 1 \\ \text { Paid employees } & 58 & 3 \\ \text { Unpaid employees } & 80 & 37\end{array}$

Source: Porgera business survey. 
periods within the SML, as royalties and compensation were paid out, though many SML residents tended to shop in Porgera Station anyway.

We make a number of observations about the more specific spatial pattern of business activity.

- Tipinini had 26 businesses, with less than 1 per cent of the total turnover in the valley, but over a third of the cash holdings, thanks to one temporarily cash-rich business.

- Kairik had 40 businesses with 8 per cent of the total valley turnover.

- Paiam had 30 businesses, but only 44 per cent of the 18 for which ownership could be determined belonged to Porgerans. Weekly turnover was K4,040, or 6 per cent of the total for the valley. Five of the owners had management training, the highest of any area.

- Suyan had 47 businesses, and the highest weekly turnover in the valley ( 44 per cent of the total), as well as the highest number of customers. Half of the 20 businesses for which ownership could be determined were owned by nonPorgerans. But it should be noted that the Ela Motors outlet is included in these figures, and this accounted for the bulk of Suyan's weekly turnover.

- Porgera Station had 40 businesses, with the highest initial investment, the highest credit levels, largest bank balances, and highest stock levels. Weekly turnover was second only to Suyan, and accounted for 19 per cent of the total valley turnover..$^{5}$ Over half the total debt recorded in the survey, half of the kai bars, the greatest number of stores with electricity, and 45 per cent of the paid staff, were located in Porgera Station. Sixty per cent of the businesses were Porgeran owned, where ownership could be identified.

- Anawe had 26 businesses, with 86 per cent being Porgeran owned. These stores accounted for 7 per cent of the weekly turnover of the Porgera Valley.

- Kulapi also had 26, and all of the 21 for which ownership could be determined were Porgeran owned. Turnover was low, accounting for just 2 per cent of the survey total. 
- Yokolama had 17 businesses in a very small area below the Yoko One camp. Only 46 per cent of the 13 businesses for which ownership could be determined were owned by Porgerans. Weekly turnover from the survey was 4 per cent of the survey total. Levels of credit were particularly high in Yokolama.

- Yuyan had 26 businesses, spread along a 5-kilometre stretch of road from the bridge over the Kaiya River to just short of Politika. Ninety-five per cent of the 21 for which ownership could be determined were Porgeran owned. Weekly turnover accounted for just 1 per cent of the survey total. Stock levels were very high, reflecting the historical importance of Yuyan as a trading centre which has declined with the growth of the Porgera mine. None of the businesses had positive bank balances.

- Panandaka had 18 businesses, which accounted for 3 per cent of the total weekly turnover. The value of stock was the lowest of any area, none of the businesses had positive bank balances, and 86 per cent of the 14 for which ownership could be determined were Porgeran owned.

- Mungalep had 32 businesses, including some on the stretch of road leading down to the Kaiya River. Ninety-five per cent of the 21 for which we were able to determine ownership were Porgeran owned, and turnover accounted for just 1 per cent of the valley total, although we were told that several more stores were generally open than was the case on the day of our visit. Credit levels were the lowest found for any area. Again, none of the owners interviewed had any money in a business bank account. ${ }^{6}$

- Yarik (including Timorope) had 29 businesses. Eighty-one per cent of the 27 where ownership could be established were Porgeran owned. Turnover accounted for 2 per cent of the valley total, and none of the owners interviewed had any money in a business bank account. Fewer customers were reported in Yarik than in any other area.

- Apalaka had 25 businesses, with a weekly turnover of just 2 per cent of the survey total. Of the 20 businesses for which I was able to establish ownership, 95 per cent were Porgeran owned.

A number of relatively distinct types of business operations could be discerned from the survey results, and I will divide the sample into 
four main categories. Clearly, not all businesses fit exactly into one or other of these categories, but they are useful as tools to discuss some of the main issues raised.

The first category, which contains at least a third of the survey sample, is made up of small-scale unsuccessful experiments in business, which are normally trade stores with corrugated iron rooves, corrugated iron walls, and wooden or dirt floors, measuring about 4 by 3 metres. One typical example was a store opened in 1989, after the owner received a K1,500 compensation payout in connection with the upgrading of the highway to Porgera. He purchased K300 worth of stock from the IPI Supa Stoa, but after this was sold it was not replaced. Income and profit from the store was used for personal consumption. The store closed in mid 1990 and had not been reopened by 1994 .

The second category consisted of small-scale ephemeral businesses. These were either 'failed experiments' in the making, or part-time stores with more social than economic value. One such store was established in 1992 with a K3,000 compensation payment which the owner received from the PJV. The roof and walls were of corrugated iron, and the dirt floor measured 6 by 5 metres. The store had K1,200 worth of stock and K100 of credit outstanding. Stock was purchased from Mount Hagen on an irregular basis. Turnover was of the order of $\mathrm{K} 20$ per day, with around 20 customers spending an average of $\mathrm{K} 1$ each. The owner stated that the store was his 'garden', and emphasised that it was not run on a strict business footing.

The third category consisted of medium-sized retail businesses, run on a more formal basis. The owner of one such business had come from Wabag and was leasing a 180 square metre building, with corrugated iron roof and walls and a concrete floor, from a local Porgeran for $\mathrm{K} 1,600 \mathrm{a}$ week. The business had electricity, a freezer, and a hot food servery. The owner began operating in late 1993 with $\mathrm{K} 600$ worth of stock. At the time of our survey, the business had K8,000 worth of stock, cash of K200, and credit outstanding of $\mathrm{K} 700$, despite the deposit scheme which the owner was trying to enforce. Seven staff were then being employed.

The fourth category comprised the largest and most serious business operations. One such wholesale and retail business occupied a building measuring over 250 square metres in area, with corrugated iron walls and roof, and a concrete slab floor. It was established in 1988 with $\mathrm{K} 4,000$, largely from money earned on the Mount Kare goldfield. The business had a pool table and dartboard, generator, a vehicle, a freezer 
and a hot food servery. The business had about $\mathrm{K} 10,000$ in cash, credit outstanding of $\mathrm{K} 1,500$ and stock valued at $\mathrm{K} 8,000$. Turnover was around $\mathrm{K} 300$ per day, with about 100 customers spending an average of $\mathrm{K} 3$ each. The business employed four paid staff and two unpaid family members, with a wage bill of around $\mathrm{K} 100$ per week. It was owned by a Porgeran with no formal management training.

From the survey data, I estimate that the approximate breakdown of the 382 businesses would be: 67 per cent in the first category (failed experiments); 18 per cent in the second (ephemeral businesses); 12 per cent in the third (medium-sized retail); and 3 per cent in the fourth (wholesale and retail).

\section{The Ipili Porgera Investments story}

IPI was incorporated as a company on 25 August 1983, at the initiative of several prominent landowners and the management of PJV. Commercial operations began in 1984, with a security contract from the mining company and a movie theatre in Alipis. Shares were promoted among the local landowners, and by 1985, around 5,000 shares, valued at $\mathrm{K} 1$ each, had been issued and paid for. A limit of 500 shares for any one individual was written into the Memorandum of Association. At this stage, the PJV provided direct management, while four Porgerans sat on the board as trustee directors.

The rise of and fall of IPI is shown in Figure 7.3. The graph shows a rapid but controlled rate of growth from 1984 to 1989. Shareholding, assets and turnover increased, and the company diversified into new areas, such as wholesale, retail, hospitality and construction, primarily by means of joint ventures. Joint venture partners were generally wellestablished companies with proven track records, such as Sullivans, Pangia and Poons. During this time, the PJV controlled IPI's strategic policy and ran the business on a day to day basis. Dividends were paid over this period (see Table 7.2), the net worth of the company increased rapidly, shareholders were happy, and the company appeared well-placed to pick up a large number of the contracts associated with the construction and operation of the mine. The SEIS noted that, as of 14 April 1987, there were 2,687 shareholders, of whom 2,014 were males and 673 female (Pacific Agribusiness 1987).

April 1989 was a turning point for the company for a number of significant reasons. Firstly, the PJV stood aside from the management of IPI, though it retained an advisory role to the board. This decision was made primarily because of the perceived conflict of interest 
between being the principal source of contracts and being the manager of the largest local contractor. IPI's independent accountant and adviser, who had been with the company since 1983, became the general manager. In 1990, he instituted a new policy direction and style of management, with three stated objectives

- to increase the wealth of the shareholders

- to be self-sufficient in management in order for IPI to establish and control its own businesses; and

- to provide employment for Porgerans and technical and management training for local businessmen.

One of the manifestations of this policy was the disassembling of the existing joint ventures. Another was a revaluation of the company's assets which allowed for a substantial loan to be obtained from the Papua New Guinea Banking Corporation (PNGBC).

This major shift in management policy coincided with the letting of the major construction contracts for mine development and associated infrastructure, such as Suyan township and Kairik airstrip. IPI picked up many of these contracts, but deficiencies in its management structure, cost control, and supervision of sub-contractors meant that

Figure 7.3 IPI asset and liability levels, and shareholders funds, 1984-93

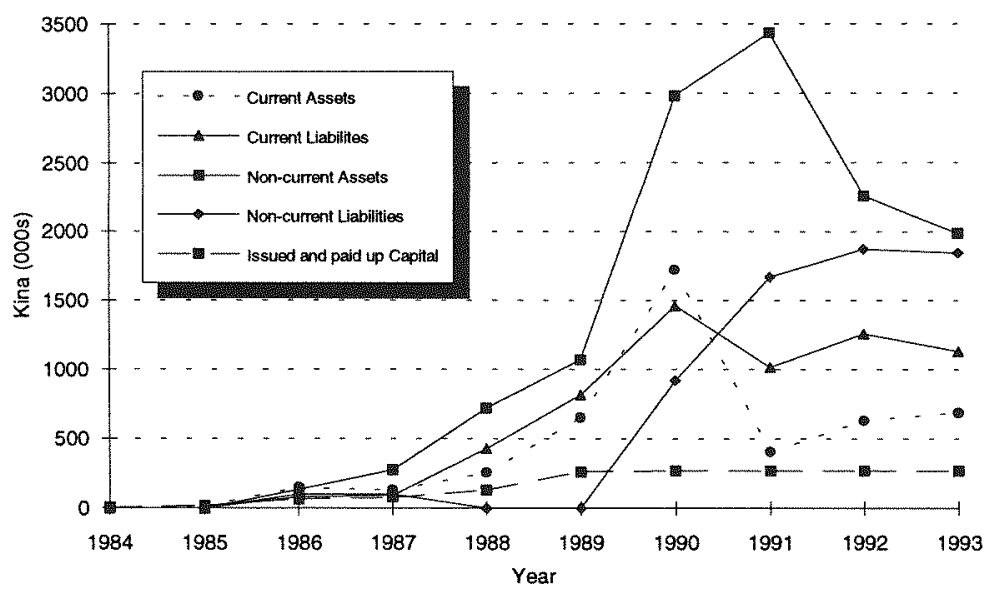

Source: IPI records. 
the company accumulated trading losses of around $\mathrm{K} 1,500,000$ during 1991 and 1992. The newly formed Ipili Porgera Construction was the major source of these losses. The extent of the problem was not clear at the time, due partly to the rapid increase in the size of the business, and partly to the fact that the company operated without a full set of accounts during that two-year period. The full extent of the problem only became obvious in early 1993, when an audit of the books was carried out, and a set of 1991 accounts was prepared. To make matters worse, the landslip at Porgera Station caused a substantial writing down of the value of IPI's equity, effectively stripping K1 million from the balance sheet. A further $\mathrm{K} 250,000$ had already been expended on drawings and initial works for a commercial centre at the station, and this was added to the losses.

These three factors-the push for 'self-sufficiency in management', the rapid expansion in the size of the business, and the landslip at Porgera Station-placed IPI in a situation where it was unable to continue trading without the support of the bank, its principal creditor. In a tripartite agreement between the board of IPI, the PNGBC and Placer Niugini, signed in December 1993, a plan was devised whereby a wholly-owned subsidiary of the PJV, known as Yelgun, would be appointed as manager in an effort to reconstruct the company.

By mid 1994, IPI was reduced to a core of profitable businesses: the Supa Stoa, the Mountain Lodge hotel, a newly established fuel station, a collection of rental properties, a security service, and a 30 per cent share in IPI-Poons joint venture which held the PJV's catering contract. The medium-term plan was to try and reduce the debt burden inherited from IPI Construction, whose interest payments were barely covered by the current trading profit. There was some hope (though no great expectation) of debt relief granted by the national or

\section{Table 7.2 IPI shareholding and dividends paid, 1986-90}

$\begin{array}{ccc}\text { Year } & \text { Issued and paid up shares } & \text { Dividend paid (kina) } \\ 1986 & 17,740 & 34,042 \\ 1987 & 75,691 & - \\ 1988 & 76,858 & 66,928 \\ 1989 & 130,685 & 31,484 \\ 1990 & 268,000 & -\end{array}$

Note: In 1989, shareholders were given a bonus 2-for-1 share offer, hence the increase in the volume of shares in 1990 .

Source: IPI records. 
provincial governments, or by the PNGBC, which was partly based on the argument that IPI was the only landowner company in PNG which had not previously received government assistance.

By November 1994, the situation had improved markedly. An interest rate reduction was granted by the PNGBC on the outstanding debt, and all arms of the company were trading well. The collapse of the Umi bridge near Lae had badly affected supply (and thus trade) for a month but, despite this setback, it was anticipated that the company would achieve a profit of $\mathrm{K} 300,000$ for 1994-the first yearend profit since 1988. Working capital was now a positive factor in the balance sheet, and this had allowed for expansion into new, generally small enterprises, such as body hire, asset recovery, and glove cleaning.

To understand the significance of this story, it is necessary to consider what IPI meant to the local community, and also what it meant to the PJV. The financial failings of IPI were brought up at a Community Issues Committee (CIC) meeting between Porgera landowner representatives and PJV Community Relations and Business Development staff in early 1993. The minutes of the meeting record that the landowner representatives were 'shamed' by the failure of IPI. They saw the role of IPI as that of picking up the big 'spin-off' contracts from the mine development, while other Porgerans got the small contracts. One leading representative said that the landowners saw IPI as an umbrella or mountain under which they could all shelter as Mount Waruwari was gradually removed by the process of mining. It is clear that IPI was seen as a symbol of the contribution of the mine to development in Porgera, which reflected as much on the Porgerans as it did on the PJV. Several landowner representatives were calling for IPI to be wound up and its assets divided up amongst the Porgeran people, yet there appeared to be a certain element of self-interest in this proposal, from those representatives who might hope to gain the distribution of assets. The general feeling, as reflected by comments at the CIC meetings, appeared to be that local people wanted IPI to succeed, and they appreciated the PJV's continued willingness to assist with the management of the company.

The PJV became involved again in the management of IPI for two related reasons: first because of its importance to the Porgerans, and the political pressure which the community thus exerted, and second because the failure of IPI would reflect badly on the PJV at the local, 
provincial and national level. There was also an element of social insurance involved, since there was a risk that the failure of IPI could be used as a weapon by groups within the community which were generally opposed to the mining company. The PJV's resident mine manager, who was also the managing director of Yelgun, said that IPI was a 'flagship' - a visible sign of the PJV's involvement in the community and its contribution to the development of Porgera. On the other hand, he did not envisage a long-term role for Yelgun in the management of IPI, and if the directors lost their battle to keep the company alive, the short-term political fall-out might have to be accepted as part of the least expensive long-term option.

\section{Porgera Joint Venture's business development efforts}

I have already pointed out that the PJV has an obligation to provide business development services in Porgera. A business development plan was first developed in 1987 to provide guidance for the direction of the company's business development efforts. This was updated in 1990, after the signing of the Mining Development Contract, and was approved by the Department of Trade and Industry. This plan was due for a further update and revision in 1994 . I shall briefly discuss the 1990 plan before reviewing the directions and efforts of the Business Development office in 1994.

The 1990 Business Development Plan (PJV 1990a) included a discussion of the constraints on business development in Porgera and Enga, similar to that presented earlier in this chapter, and a review of both business development programs in general and the activities of the PJV Business Development section in particular. In the section dealing with the implementation of the plan, the objectives of the PJV Business Development section were described as follows

[t]o assist the peoples of Papua New Guinea, but particularly the peoples of Enga Province, to improve their economic infrastructure, particularly close to the mine, to a point where they can have a meaningful and profitable input to the mine. The economic development will be of a nature that will facilitate a smooth transition for the social changes accelerated by the mine development. The infrastructure should be large enough to create an internal life of its own and not be $100 \%$ dependant on the mine market. The infrastructure will be based on commercial enterprise, not on Government or Mining company subsidies.

One point which needs to be stressed here is that the PJV was concerned to support and assist commercial, sustainable businesses; it 
was not interested in handouts. In line with this policy, and in contrast with some other resource developers in PNG, the PJV gave neither loan guarantees nor seed capital. There was also an implicit emphasis on assisting Porgerans to succeed in business in Western terms; there were no romantic ideas of adjusting Western business practices to fit the Porgeran environment. Such an 'alternative' plan, if it could be devised, might succeed in the short term, but almost certainly would not lead to a long-term, sustainable business sector at Porgera. This is not to say that the PJV's business development assistance failed to reflect the difficulties of the Porgeran business environment; only that this was secondary to the main concern to establish commercially viable businesses. The strategy adopted to achieve this objective above was to develop a commercial business centre at Porgera Station through which Porgerans and other Engans could be involved in a wide range of commercial activities. The schedule to the Business Development Plan listed 110 opportunities for future business development in a 'function list', detailing the timing and experience required to carry out each function. Of these 110 functions, $12 \mathrm{implied}$ the presence of non-Engan interests as joint venture partners. Approximately one-third of them had been established by 1994. The biggest impediment for most of the rest had been the lack of land for commercial development.

In 1994, the PJV Business Development section had a professional staff of eight-two expatriate managers, three accountants, and three business development officers (two in Porgera and one in Wabag). ${ }^{7}$ In the Porgera office, much of their effort was directed at the maintenance of existing contracts, primarily assisting the contractors with administrative and accounting functions. The demand for such assistance had grown since the Internal Revenue Commission required that all PJV contractors have a current Tax Compliance Certificate. The Business Development section also had an important reporting function, compiling quarterly reports for the Department of Trade and Industry Goods and Services Committee (DTIGSC) on the PJV's compliance with the various development agreements, as well as attending its quarterly meetings. ${ }^{8}$ Another focus was the discovery and negotiation of new contract opportunities arising from the current mining operation. There were a number of projects in the pipeline (both mine-related and non-mine related), including

- the recovery and resale of low-cost mine assets

- various services connected to the development of Paiam 
township, including a bank, a pharmacy, a commercial centre, a PJV Community Affairs office building, a motor dealer, and tyre sales; and

- the revitalisation of a viable local sawmill, following the closure of the two which were covered by our own survey.

There was also an initiative to establish 'offshore' investment programs for individual Porgerans, which could be considered as a more sustainable use of compensation funds, even if it meant that capital was lost to the local Porgeran economy in the short term. For it could reasonably be argued that it was more productive and sustainable to have the returns from these investments enter the local economy over time than to have the capital injected immediately into a business which was likely to fail.

\section{The bigger picture}

It is clear that the Porgeran business community had a very limited range of activities and options in 1994. This was a characteristic shared with most other rural areas of Papua New Guinea, the main difference being that Porgera had far more money to spend. On the other hand, Porgera is a difficult business environment, even for a well managed business. Apart from the location constraints and the lack of secure land titles, the local economy has also suffered from an uneven level of PJV inputs, most especially in respect of monthly variations in the amount of compensation payments (see Chapter 3 ). The volatile social environment has increased security costs for businesses, both the cost of insurance and the wages of security guards, while the banks have grown nervous about lending money for businesses in Porgera.

For Porgerans, the social and cultural obligations which follow from possession of a successful business reduce their ability to continue to reinvest funds into the business. In the case of IPI, the demands made by directors on the company (for vehicles and other perks) may not have been the main cause of the company's financial problems, but do serve to illustrate the way in which personal and business interests seem to invariably become confused. Interestingly, only one of the successful Porgeran businessmen we spoke to felt that he had this problem under control. The others all noted this as the biggest problem which their businesses faced, and were well aware of the potential impact of the intrusion of personal matters into the business sphere (see Finney 1987:63-4). 
There are ways for businessmen to reduce the pressure to distribute their business earnings. Biersack (1980) has observed that conspicuous wealth and consumption make a person more vulnerable to the requests and expectations of kin, although the sharing of this wealth and consumption is also the means by which prestige has been obtained in the past. Several Porgeran trade store owners had found that they were better off renting out their shops to non-Porgerans and simply collecting the rent, because this was a less visible form of accumulation. A number of Porgerans were investing in other parts of the Highlands, in Port Moresby and even overseas, partly as a means of keeping a distance between their wealth and their kin obligations, partly to reduce the visibility of their capital accumulation, and thus to limit the pressure to distribute these resources, and partly because of the greater investment opportunities which existed outside Porgera.

The other major finding of our own survey was the almost total lack of business training among Porgerans. Although business experience can be a substitute for formal training, it is unlikely to be useful if the businesses continually fail. Training in all the most basic aspects of business management was in high demand in the community, and would undoubtedly have improved the performance of many of the businesses surveyed. On the negative side, the training of businessmen and women would lead to the closure of many of the stores, because the reason why the area has been able to support so many stores is that most have been run unprofitably. The PJV Business Development section involved the Small Business Development Corporation in running business training courses in Porgera. These were initially well attended, but the level of attendance subsequently declined as a result of various problems in the organisation of the courses. Our own survey results suggested that there was still a demand for training courses among local business owners, and a new training programme had been developed in November 1994, which covered basic business and book-keeping skills.

\section{Mining company contracts}

The supply of goods and services to the PJV has been arranged through contracts which are issued in accordance with Clause 14 of the Mining Development Contract. The essential features of this clause are repeated in each of the quarterly review reports submitted to the DTIGSC.

[P]reference [will] be given to:

1. Porgerans;

2. Engans; 
3. Other Papua New Guineans;

4. International companies,

provided:

1. there is no impact on schedule;

2. the specifications are adhered to; and

3 . the cost is competitive.

Contracts at Porgera have been a source of contention, at both the local and provincial levels, largely because of misconceptions about what a 'contract' is. In addition, the PJV has been unnecessarily defensive in its presentation of the contract figures, which therefore merit closer examination. In this section, I shall also consider the types of contract which have been issued, and their real value to the Porgeran business community.

\section{The numbers}

The construction and operation of the Porgera mine have been handled by separate entities-Placer Dome Construction and the PJV respectively. As a result, despite the substantial temporal overlap between these two phases of development, contracts have also been divided between these two categories. The third (June-September) quarterly review report to the DTIGSC for 1993 (PJV 1994) provided details on the final figures for the construction phase, because construction officially ended with the completion of Stage IVa in October 1993.

- A total of 322 construction contracts were awarded between 14 February 1989 and the end of October 1993, with a total value of $\mathrm{K} 184,344,863$.

- Porgeran contractors (including joint ventures) received 80 contracts (or 25 per cent of the total number) with an actual value of K29.16 million (or 16 per cent of the total value).

- Other Engan contractors (including joint ventures) received 88 contracts (or 27 per cent of the total number) with an actual value of $\mathrm{K} 34.17$ million (or 18 per cent of the total value).

The report went on to state that such figures 'demonstrate clearly that the terms of the SML agreement... have been met during the four stages of construction at Porgera'.

The fourth (October-December) quarterly review report for 1993 provided comparable data on the contracts awarded under the heading of 'operations'. 
- A total of 721 operations contracts were awarded between 1983 and the end of December 1993, with a total value of K99.8 million.

- Porgeran contractors (including joint ventures) received 353 contracts (or 49 per cent of the total number) with an actual value of K24.4 million (or 24.4 per cent of the total value) of these contracts.

- Other Engan contractors (including joint ventures) received 198 contracts (or 27.4 per cent of the total number) with an actual value of $\mathrm{K} 28.9$ million (or 29 per cent of the total value) of these contracts.

The report also noted that recent increases in the value of contracts awarded to Ipili-speakers 'indicates the maintenance of the preference clause'.

Closer examination of the Porgeran contract figures shows why they have been contentious. Of the 80 Porgeran construction contracts

- 31 went to youth or women's groups for 'environmental rehabilitation' (tree planting)-these were all relatively small, labour-only contracts

- 18 were for plant hire, and two were for road maintenance equipment

- 17 were for construction projects, including the PJV Environment and Assay buildings, Paiam school, relocation housing, Suyan township housing, and the like

- 12 were for freight, garbage disposal, and catering services. Twenty-eight of the contracts, including all the construction contracts, went to IPI, either separately or in association with joint venture partners. Only 14 of the Porgeran contracts were worth more than $\mathrm{K} 500,000$ (six for plant hire, three for catering, and five for construction), and ten of these went to IPI.

Rather than examine the full total of 353 operations contracts awarded to Porgerans, it is more manageable to discuss the 57 contracts which were still current in 1994 . These contracts were generally representative of the range of operations contracts awarded, except for the fact that they excluded the 'field contracts', which I shall discuss separately. Of these 57 contracts

- 19 were for bus hire

- 14 were for plant hire

- seven were freight contracts

- three were for hire of labour 
- three were for security services

- two were for catering services

- two were for garbage collection; and

- there was one contract each for incinerator operation, SML fence construction, market construction, sewage truck, cleaning, vegetable supply, and animal capture and disposal. ${ }^{9}$

These contracts had a total value of just over K18 million, which represented about three-quarters of the value of all the operations contracts awarded to Porgerans to date. But an important qualification needs to be made about the value of these contracts. In all but three cases, they were paid on a 'rates' basis, which meant that the value of the contracts as represented in the quarterly reports was an estimate of what the contractor could usually be expected to earn over the life of the contract. In practice, few Porgeran bus, freight and plant contractors were actually able to realise these amounts for a number of reasons, including an inability to provide reliable service, occasional lack of work, and maintenance problems. The bus hire situation illustrates this perfectly. There were 21 PJV bus hire contracts in 1994, although it was acknowledged by the company that there was only work for 15 buses. The greater number of contracts was required so that, on any one day, at least 15 buses would turn up for work. This was because there had been problems with buses failing to turn up, especially during holiday periods when the owners were apparently liable to use them for personal business.

As a result, there was a substantial difference between the expected value of the contracts and the actual amount paid to date. The fourth quarterly report, for example, showed that, while the total value of the contracts awarded to Porgerans was K24.4 million, the amount actually paid to Porgeran contractors to date was only K15 million. The actual value of contracts paid was only being adjusted at the end of those contracts.

A further point raised by the landowners was that the full value of any contract awarded to a joint venture between a Porgeran and a non-Porgeran entity was being counted as the value of a 'Porgeran' contract. For example, the full value of the IPI-Poons catering contract was included in the Porgeran category, despite the fact that IPI only held a 30 per cent interest in the joint venture. Of course, the proportion of the total value of the contract which actually remained in Porgera might well have been greater than the equity share of the Porgeran partner in the joint venture, once the value of local wages 
and other local purchases was taken into account, but the PJV was preparing to acknowledge the point at issue by amending its method of calculating Porgeran contract values.

Given the local cultural constraints on business development and the high-technology inputs required by the mining company, the contract figures reflect well enough on the PJV's efforts. With a few exceptions, Porgerans were given all the contracts which they were qualified to carry out. Porgeran representatives have sometimes argued that Porgerans should be given contracts even if they are not qualified to carry them out, as they will pick up the necessary skills as they go along or else subcontract the work to someone else, but this is simply not feasible when one considers the often highly skilled nature of the mining operation and the tight schedules which require that contracts be completed quickly.

\section{What is a contract?}

The 'contract' has been seen by many Porgerans as the key to success in business, but the reality of the Porgeran business environment in 1994 was that a PJV contract had more status value than economic value. There were remarkably few Porgeran contractors who were actually making money from the project. Furthermore, most of the value of many Porgeran contracts was accounted for by goods (for example fuel and plant) purchased from outside Porgera, and there were some contracts to which the Porgeran contractor was contributing very little indeed. I shall now consider a number of specific contract types in order to assess both their projected and actual profitability, and the proportion of the value of 'Porgeran' contracts which actually accrued to Porgerans. Four specific types of contracts are discussed: freight, bus hire, field contracts, and operational contracts. In each case, a typical contract (rather than any actual contract) is considered in light of the figures discussed with me by the contractors themselves and by PJV staff.

A bus contract was typically listed as being worth $K 60,000$ over two years, though this figure underestimates the amount that could be earned, because it represents the average of what was actually being realised by the contractors. Bus contractors were paid at a rate of $\mathrm{K} 30$ per hour. Assuming a five-hour day and a six-day week, this would have meant a gross income of $\mathrm{K} 900$ per week or $\mathrm{K} 45,000$ per year. The bus contracts were put together in such a way that a Porgeran could use his contract as a means of obtaining a bank loan to buy a new $\mathrm{PMV}$, worth around $\mathrm{K} 34,000$, and pay off the loan over the two-year 
life of the contract. Repayments on such loans were about $\mathrm{K} 1,600$ a month in 1994. In theory, then, after two years, the bus contractor should own the bus and have made a significant profit which can be reinvested in the business. In practice, none of the bus owners were making profits of this order, and after two years, most of the buses were not in a suitable condition to continue operating on a PJV contract. The main problem was the lack of spending on repairs and maintenance, which in turn led to the owners being unable to provide a consistent and reliable service.

If we look at the budget breakdown (Table 7.3) in terms of final destination of the money being spent, we can safely say that all of the loan repayments and at least 75 per cent of the running costs (fuel, tyres and repairs and maintenance) accrued to non-Porgeran businesses, leaving a maximum of 42 per cent of the contract value to accrue in Porgera. Furthermore, most of the bus drivers were nonPorgerans recruited by the Porgeran contractor, thus reducing the proportion even further. And since the number of bus contracts exceeded the volume of available work, for reasons already mentioned, there would only be an average of 3-4 hours of work for each bus on those days when all the buses showed up for workbarely enough to meet the financial commitments of the owners. ${ }^{10}$

Although I could not construct a budget for a typical freight contract the following information does allow some comments to be made. In 1994, the PJV was paying K165 per tonne for freight from Lae to Porgera. For a typical 24-tonne load, this was equivalent to $\mathrm{K} 3,970$ per trip. A semi-trailer should be able to average four loads a month, while a twin-steer truck could complete five, and some of the new trucks were managing more. Average annual income should therefore

Table 7.3 Typical two-year bus contract budget, 1994

Item

Loan repayments for bus purchase

Driver's wages

Fuel

Tyres and tubes

Repairs and maintenance

Profit

Total
Kina

38,000

7,000

10,000

4,200

12,000

20,000

89,200

Source: PJV Business Development records. 
have been $\mathrm{K} 190,000$ for a semi-trailer and $\mathrm{K} 238,000$ for a twin-steer. The PJV provided some assistance with fuel and tyres, and sometimes also had backloads needing transport down to Lae. The contractors could also secure backloads from other sources, and some of the larger, non-Porgeran companies were certainly doing so. The PJV considered that its freight rates had a K10 per tonne 'Porgeran factor' built in to cover the additional expenses involved in working in the Porgeran environment. The company's own estimate was that there should have been a profit of $\mathrm{K} 1,000$ per trip for the operators. And yet, like the bus owners, all the Porgeran freight contractors were in trouble, and this could once again be put down to a lack of maintenance and a lack of management. Freight contracts do require greater organisation than bus contracts, and even one missed trip could cost the operator a great deal. Several Porgerans had previously shown that it was possible to make profits from freight contracts, but only one or two had used the profits to consolidate their businesses, and at least one previously successful freight contractor had subsequently folded due to a lack of attention to the maintenance of the business.

The incinerator contract held by a Porgeran business group highlights many of the problems of what I call 'operational contracts' in the Porgeran business environment, and also the means by which these can be overcome. The PJV had constructed the high-temperature incinerator to dispose of the combustible waste generated by the mine. The contract to operate the incinerator was originally awarded to the business group in May 1993. In December 1993, a garnishee order was taken out on the contract earnings by a creditor of one of the two principals. Apparently, the money was owed for personal expenses which were unrelated to the business group. With assistance from the PJV, the group was able to continue operating, and the money was repaid. The principal involved agreed to step aside, and the contract was transferred to the other principal's own business group. In March 1994, Kulapi villagers living in the vicinity of the incinerator complained that this person was feeding his pigs on garden waste which should have been burnt in the incinerator. This claim was vehemently denied by the person involved, who believed that others in Kulapi were jealous of his success.

These two incidents highlight the way in which personal matters come to impinge on all types of businesses in Porgera. Unless the business owner is able to deal with such problems, the contract will be lost, and the business will fail. In the case of this particular contract, 
the support of the PJV was essential for survival. The business group was paid a guaranteed set rate each week, and employed eight staff, including the principal. Three of these staff were Porgerans, while the rest were from other parts of Enga. The projected cashflows showed that wages accounted for about 60 per cent of the value of the contract, other running costs accounted for about 25 per cent, and the remainder was potentially profit. When interviewed in late March 1994, the principal was finding the contract rather tight financially, but felt that he would be able to reduce costs to give a better return. The ongoing nature of the incinerator contract was typical of several of the operational contracts awarded to Porgerans: the sewage truck and the rubbish contract were two other examples. They allowed a steady source of income which could potentially be used as a source of longterm investment inside or outside Porgera.

Most of the operations contracts issued by 1994 were 'field contracts'. The PJV's contract listing indicated that these were a relatively recent phenomenon, because it showed that more than 180 field contracts had been issued to Porgerans since February 1993, but it seems that they had simply not been captured by the contract reporting system before that time. Field contracts are generally shortterm, labour-only contracts which are relatively low value and thus not even regarded as 'business' by some Porgerans. They have been let for revegetation, scrub clearing, relocation garden clearing, relocation house construction and the like. Most have been let to individuals, youth groups or women's groups. Although they were generally valued at less than $\mathrm{K} 2,000$, the field contracts had the advantage that virtually all of this value accrued to Porgerans. In this respect, ten $\mathrm{K} 2,000$ field contracts are worth as much as a K100,000 contract from which only 20 per cent of the value stays in Porgera. On the other hand, the potential for investment of funds derived from the field contracts has rarely been realised, and this point has commonly been overlooked because the field contract has not had the status of the higher value, capital intensive contracts. 


\section{Notes}

1 Businesswomen, while not totally absent, were very rare.

2 In the first half of 1994, 47 per cent of the value of PJV Warehouse purchase orders went to national suppliers.

3 The consultant made unrealistic assumptions, such as treating Porgera as a 'closed' economy, and then constructed a model of this economy which contained faulty equations, with input figures which misrepresented the relevant factors.

4 Gibbs (cited in Pacific Agribusiness 1987) had counted 25 'passenger vehicles' owned by the Ipili in 1979.

5 If the IPI Supa Stoa and Paiam Kumbipara operations were included in the figures, the predominance of Porgera Station as the economic heart of the valley would be further underlined. The current IPI Supa Stoa weekly turnover (one-third retail and twothirds wholesale), for example, was equal to that of all other business combined.

6 By November 1994, business in Mungalep had virtually ceased to exist as a result of a large-scale tribal fight which had destroyed a number of the trade stores surveyed in March. The largest businessman in Mungalep was one of the central protagonists.

7 The Wabag office was intent on revitalising the Enga Vegetable Marketing Depot as a source of supply for the PJV caterers at Porgera, as well as other regional markets, and on providing assistance to reopen the local pyrethrum factory.

8 The government had two business development officers of its own based in Porgera, but their capacity to operate independently of the PJV's Business Development section was limited by their lack of a vehicle.

9 I would query some of these figures. The market construction contract, for example, was awarded to the 'Hiwanda landowners', who are thought to reside in the Southern Highlands Province, while two of the plant hire contracts were no longer current, and there appeared to be duplicate records for security, garbage collection and catering. Removal of these anomalies reduced the number of Porgeran contracts to 51.

10 By November 1994, the devaluation of the PNG kina had changed the financial parameters substantially. A new PMV now cost $\mathrm{K} 57,000$, and the cost of fuel, tyres and repairs had also gone up. The PJV had increased its contract rate from $\mathrm{K} 30$ to $\mathrm{K} 33$ per hour. The profitability of bus contracts also seemed to have improved, because half of the contractors had made enough money to buy new buses since April that year. IPI owned three of the bus contracts, and were managing several others for local Porgeran owners. 